\title{
EL CONTROL DE LA TRANSPARENCIA. LAS NUEVAS Y LAS VIEJAS FUNCIONES DEL VALEDOR DO POBO EN MATERIA DE TRANSPARENCIA
}

Control of transparency. The new and traditional functions of valedor do pobo on Transparency

DOI: http://dx.doi.org/10.15304/dereito.27.Ext.5792

FERnANDo LUIS de ANDRÉS Alonso

Secretario General

Valedor do Pobo

f.deandres@valedordopobo.gal

\section{Resumen}

La transparencia es un valor fundamental de la democracia. En los últimos tiempos, su reconocimiento legal y sus garantías se han desarrollado extraordinariamente en España con la aprobación de la LETAI. Esta norma destaca por sus innovaciones sustantivas y también, de forma principal, por la configuración de un específico régimen de garantías. En él participan algunos órganos de nueva creación y otros ya existentes, como los defensores del pueblo, que aportan su indudable condición de instituciones independientes. El Valedor do Pobo (el defensor del pueblo de Galicia) ya era protagonista en el control de la transparencia. La ley gallega 1/2016, de transparencia y buen gobierno le atribuye otras funciones de diferente naturaleza como Comisionado da Transparencia y pieza fundamental de la Comisión da Transparencia.

Palabras clave: transparencia; Valedor do Pobo; comisionado; gobierno abierto

\section{Abstract}

Transparency is a fundamental value of democracy. In recent times, its legal recognition and guarantees have been remarkably developed in Spain with the approval of LETAI, Access to Public Information and Good Governance. This rule stands out for its substantive innovations and particularly by setting a specific guarantees scheme. Some newly created bodies and a number of existing institutions as ombudsmen have been involved in this area. Ombudsman adds their valuable condition of being independent institutions. The Valedor do Pobo (the ombudsman of Galicia) already had a leading role in controlling transparency. The galician Law on Transparency and Good Governance gives it another functions of different nature as Transparency Commissioner and fundamental part of the Commission of Transparency.

Keywords: transparency; Valedor do Pobo; commissioner; open government.

Recibido: 10/12/2017. Aceptado: 09/09/2018. 


\section{SUMARIO}

1. EL VALOR DE LA TRANSPARENCIA.;- 2. EL DESARROLLO DE LA TRANSPARENCIA.;- 3. LA EVOLUCIÓN LEGAL DE LA TRANSPARENCIA EN ESPAÑA.;- 4. EL CONTROL DE LA TRANSPARENCIA EN LA LETAI.;- 5. EL VALEDOR DO POBO COMO COMISIONADO DE LA TRANSPARENCIA Y PROTAGONISTA DE LA COMISIÓN DE TRANSPARENCIA.;- 6. NUEVAS Y VIEJAS FUNCIONES DEL VALEDOR DO POBO EN MATERIA DE TRANSPARENCIA.; 7. BIBLIOGRAFÍA.

\section{EL VALOR DE LA TRANSPARENCIA}

La aplicación del principio de transparencia a los poderes y agentes públicos, su control y garantía, son elementos centrales de los sistemas democráticos. Por ello es frecuente subrayar la íntima relación entre el desarrollo democrático y la profundización y salvaguardia de la transparencia. En los últimos tiempos se ha puesto mayor énfasis en la necesidad de perfeccionar los cauces de participación ciudadana y, como premisa para ello, el acceso a la información pública. La complejidad de las sociedades democráticas y la necesidad de preservar los medios de control ciudadanos hacen que este principio se convierta en uno de los puntos clave de lo que se conoce como calidad democrática ${ }^{1}$.

De esta forma, en los modernos Estados democráticos la transparencia es esencial, o al menos un parámetro que permite realizar un juicio certero sobre si se trata de una democracia avanzada. Hasta tal punto es así que resulta común dudar de su correcto funcionamiento cuando los asuntos públicos se gestionan con déficits informativos o de forma oscurantista u opaca". Se trata de uno de los "pilares fundamentales de las democracias", puesto que la información es del ciudadano, no del Estado ${ }^{3}$. En sentido inverso, con los avances en materia de transparencia se legitima la acción continuada de los poderes públicos y se previene contra la proliferación de riesgos para la democracia y su buen funcionamiento, en especial que la corrupción alcance niveles insoportables para la ciudadanía. Por ello, algunos autores llegan a afirmar que la transparencia es un elemento estructural de todo Estado democrático ${ }^{4}$.

J. J. FERNÁNDEZ RODRÍGUEZ, Defensorías del Pueblo en España: una visión prospectiva, Universidad de Alcalá de Henares, 2014, p. 75, sostiene que "en el nuevo entorno de la democracia participativa y deliberativa la transparencia cobra, si cabe, más fuerza. Sólo con su funcionamiento puede ser real el pluralismo, la participación y el proceso de control que ejerce la ciudadanía".

2 M. A. SENDÍN GARCÍA, "Transparencia y acceso a la información pública", en J. Rodríguez Arana y M. A. Sendín García, Transparencia, acceso a la información y buen gobierno, Comares, Granada, 2014, p. 93. También incide en esta idea D. ORDÓÑEZ SOLÍS, "El derecho de información del ciudadano, la protección de datos personales y la transparencia de la Administración", en Revista del Poder Judicial, núm. 73, 2004.

3 Así lo resalta el Informe del relator especial de NU para la libertad de opinión y expresión de 2000, titulado Promoción y protección del derecho a la libertad de opinión y expresión, ONU Doc. E/CN.4/2000/63, 18 enero 2000, en especial pp. 30 y ss.

${ }^{4}$ M. A. SENDÍN GARCÍA, "Transparencia y acceso a la información pública", op. cit., p. 99. 
La relevancia de la transparencia y la información pública para los derechos humanos se destaca en el último Informe de la Federación Iberoamericana del Ombudsman, que acertadamente señala que "cada vez existe mayor acuerdo en afirmar que sin democracia no hay derechos humanos que valgan, que democracia es sobre todo participación de la ciudadanía en los asuntos públicos, y que no hay participación posible sin la previa apropiación, por todas las personas, de la información pública necesaria para conocer, y en su caso criticar y proponer" ${ }^{\prime 5}$. Esta idea se encuentra fortalecida a nivel mundial y especificada en el concepto de gobierno abierto, especialmente desde el acceso a la presidencia de los EE.UU. del presidente Barack Obama, que subrayó la necesidad de "asegurar la confianza pública y establecer un sistema de transparencia, participación pública y colaboración", esto es, una apertura que fortalezca la democracia 6 .

\section{LA DESARROLLO DE LA TRANSPARENCIA}

Dado que estamos tratando un elemento esencial para el sistema democrático, su actual configuración constitucional y legal resulta de la lógica evolución para profundizar en sus exigencias. Ya las primeras declaraciones de derechos surgidas de las revoluciones liberales aludían a la necesidad de garantizar la transparencia, y así la Declaración de Derechos del Hombre y del Ciudadano de 1789 señalaba que "la sociedad tiene derecho a pedir cuentas de su gestión a todo agente público de su administración" (art. 15).

En el ámbito internacional se reconoce el derecho a investigar y recibir informaciones o a la libertad de buscar, recibir y difundir informaciones e ideas (art. 19 DUDH y art. 19. 2 PIDCP) ${ }^{7}$. Este derecho-libertad será el punto de partida del que derivará la configuración independiente de la garantía de acceso a la información pública como derecho fundamental, constitucional o legal, pero en cualquier caso básico para el funcionamiento democrático del Estado. Esta derivación se desarrolla por la Relatoría Especial de NU para la Libertad de Opinión y Expresión desde su informe de 1998, en el que señala que el art. 19 PIDCP conlleva "una obligación positiva sobre los Estados para asegurar el acceso a la información, particularmente respecto a la información que está en manos

\footnotetext{
${ }^{5}$ VV.AA., Transparencia e información pública, XIII Informe sobre derechos humanos, Federación Iberoamericana del Ombudsman, Trama Editorial, Madrid, 2015, págs. 15-16. 6 Memorando de Obama sobre Transparencia y Open Government de 8.12.09, en http://goo.gl/aTB8P.

${ }^{7}$ El art. 19 de la Declaración Universal de Derechos Humanos (DUDH) dispone que "todo individuo tiene derecho a la libertad de opinión y de expresión; este derecho incluye el de no ser molestado a causa de sus opiniones, el de investigar y recibir informaciones y opiniones, y el de difundirlas, sin limitación de fronteras, por cualquier medio de expresión". En términos similares el Pacto Internacional de Derechos Civiles y Políticos (PIDCP), en su art. 19 reconoce que "... toda persona tiene derecho a la libertad de expresión; este derecho comprende la libertad de buscar, recibir y difundir informaciones e ideas de toda índole, sin consideración de fronteras, ya sea oralmente, por escrito o en forma impresa o artística, o por cualquier otro procedimiento de su elección...".
} 
del Gobierno en todo tipo de sistema de almacenamiento y recuperación"; o, en definitiva, el "derecho de acceso a la información en poder del Estado" como uno de los "fundamentos de la democracia representativa" (Informe de 1999).

A partir del reconocimiento de la nueva configuración del derecho a la transparencia y al acceso a la información pública, su desarrollo ha resultado ingente en los organismos internacionales, y la mayor parte de los Estados democráticos han realizado una labor de profundización tanto en su reconocimiento como en la gestión de las obligaciones públicas derivadas de él.

\section{EL EVOLUCIÓN LEGAL DE LA TRANSPARENCIA EN ESPAÑA}

Nuestra Constitución reconoce el carácter esencial de la participación política de los ciudadanos (art. 9.2) en el marco del Estado social y Democrático de Derecho (art. 1.1). Esta participación no es posible sin transparencia, por lo que el presupuesto de la participación debe considerarse constitucionalizado. Además, de acuerdo con los postulados internacionales que examinamos, el reconocimiento constitucional de la transparencia deriva del derecho a comunicar y recibir libremente información (art. $20 \mathrm{CE}$ ). En términos más concretos y directamente relacionados con la transparencia se reconoce el derecho de acceso a los archivos y registros administrativos (art. 105 b CE).

A pesar de su entronque constitucional, el derecho de acceso a la información pública o a la transparencia hasta hace bien poco tuvo un desarrollo legal deficiente. Venía dado fundamentalmente por la Ley 30/1992, de 26 de noviembre, de régimen jurídico de las administraciones públicas y procedimiento administrativo común (LRJAP-PAC), que preveía el principio de transparencia como uno de los principios informadores del procedimiento administrativo general de todas las administraciones (art. 3.5 LRJAP-PAC) y regulaba alguna de sus manifestaciones concretas. Lo hacía en relación con los procedimientos en los que la posición del ciudadano era cualificada por concurrir la condición de interesado, un concepto que ha ido experimentando una interpretación extensiva, pero también cuando no concurría esa condición, en cuyo caso se atribuía la posibilidad de acceder a los archivos y registros (art. 37 LRJAP-PAC). No obstante, su desarrollo práctico resultó escaso y con él no podía entenderse que se colmaran las exigencias crecientes de la transparencia. En el ámbito municipal se preveían más amplias posibilidades de acceso ciudadano a los asuntos de la "vida local" (art. 69.1 de la Ley 7/1985, de 2 de abril, reguladora de las bases de régimen local).

Posteriormente la transparencia se fue abriendo camino en determinados sectores del ordenamiento que afectaban a la esfera general de los ciudadanos al margen de las posiciones subjetivas en cada asunto. Así sucedió en la legislación medioambiental, al aprobarse la Ley 37/2006, de 18 de julio, por la que se regulan los derechos de acceso a la información, de participación pública y de acceso a la justicia en materia de medio ambiente. 
La aprobación de la LETAI ha supuesto un considerable avance en las previsiones sustantivas y las garantías para acceder a la información pública. Como desarrollo de sus presupuestos constitucionales, la nueva ley supone el establecimiento de obligaciones para todas las administraciones y para algunas instituciones no públicas, el reconocimiento de derechos subjetivos de los ciudadanos para acceder a la información en sus manos, y el establecimiento de garantías administrativas específicas mediante la creación de instancias independientes, que junto con los mecanismos ordinarios de naturaleza judicial garantizan su efectividad.

A la ley estatal se suman numerosas leyes autonómicas y disposiciones municipales. Dedicaremos especial atención a la LGT, que atribuye al Valedor do Pobo la condición de Comisionado da Transparencia e incardina en su seno la Comisión da Transparencia. No obstante, el esqueleto principal del sistema de control de la transparencia se establece en la legislación estatal, por lo que antes examinaremos ésta con atención, con el fin de determinar con posterioridad las no pocas particularidades de la normativa autonómica y de su entramado institucional.

\section{EL CONTROL DE LA TRANSPARENCIA EN LA LETAI}

La LETAI crea el Consejo de Transparencia y Buen Gobierno como órgano encargado del control administrativo de los derechos en esas materias. Al Consejo se atribuye la función de controlar el cumplimiento de las obligaciones en materia de publicidad activa (art. 9) ${ }^{8}$ y conocer las reclamaciones que se promuevan contra las resoluciones de las solicitudes de acceso a la información pública (arts. 23 y 24$)^{9}$. Así mismo se le

${ }^{8}$ La primera función se especifica en el art. 9 (control de la publicidad activa) de la siguiente forma: "1. El cumplimiento por la Administración General del Estado de las obligaciones contenidas en este capítulo será objeto de control por parte del Consejo de Transparencia y Buen Gobierno. 2. En ejercicio de la competencia prevista en el apartado anterior, el Consejo de Transparencia y Buen Gobierno, de acuerdo con el procedimiento que se prevea reglamentariamente, podrá dictar resoluciones en las que se establezcan las medidas que sea necesario adoptar para el cese del incumplimiento y el inicio de las actuaciones disciplinarias que procedan. 3. El incumplimiento reiterado de las obligaciones de publicidad activa reguladas en este capítulo tendrá la consideración de infracción grave a los efectos de aplicación a sus responsables del régimen disciplinario previsto en la correspondiente normativa reguladora".

9 La sección $3^{a}$ del Capítulo III (régimen de impugnaciones) contiene el art. 24 (reclamación ante el Consejo de Transparencia y Buen Gobierno), que señala: "1. Frente a toda resolución expresa o presunta en materia de acceso podrá interponerse una reclamación ante el Consejo de Transparencia y Buen Gobierno, con carácter potestativo y previo a su impugnación en vía contencioso-administrativa. (...) 6. La competencia para conocer de dichas reclamaciones corresponderá al Consejo de Transparencia y Buen Gobierno, salvo en aquellos supuestos en que las comunidades autónomas atribuyan dicha competencia a un órgano específico, de acuerdo con lo establecido en la disposición adicional cuarta de esta Ley". También contiene el art. 23 (recursos), que prevé que "la reclamación prevista en el artículo siguiente tendrá la consideración de sustitutiva de los recursos administrativos, de conformidad con lo dispuesto en el art. 107.2 de la Ley 30/1992, de 26 de noviembre, de Régimen Jurídico de las Administraciones Públicas y del Procedimiento Administrativo Común (1). No obstante lo dispuesto en el apartado 
encomiendan funciones de carácter general en materia de transparencia (art. 38).

La legislación estatal afecta a todas las administraciones y entidades concernidas de un amplio listado. Aunque en una primera fase de su aplicación sólo afectó a las de ámbito estatal, a partir de su plena aplicación desde diciembre de 2015 , su contenido material afecta a todas las administraciones y entidades. No obstante, el Consejo de Transparencia y Buen Gobierno no tiene competencias en las comunidades autónomas con las que no haya suscrito un convenio al efecto, por lo que en esos casos la competencia de control debe ejercerse por el órgano autonómico que se designe por cada comunidad autónoma. Esta circunstancia hizo dudar sobre lo que debía ocurrir en caso de que no se constituyeran los órganos autonómicos después de la plena vigencia de la ley. Se planteó la posibilidad de que fuera el Consejo estatal quien asumiera provisionalmente esa función hasta tanto lo hicieran los órganos autonómicos; sin embargo, el propio Consejo descartó categóricamente esa posibilidad, con el apoyo de un informe de la Abogacía del Estado, al interpretar que con ello violaría el principio constitucional de autonomía de las comunidades autónomas, de acuerdo con reiterada jurisprudencia del Tribunal Constitucional. Esta circunstancia dio lugar a que durante un tiempo limitado no existieran órganos específicos de control en algunas comunidades autónomas, como sucedió en Galicia hasta la aprobación de la ley autonómica y la creación y puesta en marcha de la Comisión gallega. En este caso, la duda planteada con carácter general era el régimen de recursos que correspondía atribuir a los actos, expresos o presuntos, que resolvían las solicitudes de acceso, que ya se estaban produciendo en las administraciones gallegas. La respuesta fue remitir a los posibles reclamantes al régimen general de los recursos -el de la LRJAP-PAC-, a la vista de la imposibilidad material de utilizar la vía sustitutiva prevista en la normativa de transparencia.

Como vimos, la LETAI permite que las comunidades autónomas puedan crear su propio órgano de control o atribuir la función en su ámbito al Consejo estatal mediante convenio, como sucedió en La Rioja. Esto sólo se da en caso de pleno acuerdo, incluida la compensación económica al Consejo estatal por el desempeño de la función (Disposición adicional cuarta LETAI). De ello resulta que si cualquiera de las dos partes no acepta los términos del acuerdo éste no se producirá y por ello resultará obligada para la C.A. la creación de un órgano en su propio ámbito.

\subsection{El control del cumplimiento de las obligaciones en materia de publicidad activa}

La función que corresponde al Consejo de Transparencia y Buen Gobierno respecto de la publicidad activa se concreta en el control del adecuado cumplimiento de las obligaciones referidas en el Capítulo II del Título I LETAI, esto es, las relativas a la publicidad que de oficio corresponde 
difundir a las administraciones -en este caso, a la Administración General del Estado- de forma periódica y actualizada. Deben incluirse contenidos de información institucional, organizativa y de planificación (art. 6), información de relevancia jurídica (art. 7), e información económica, presupuestaria y estadística (art. 8). A ello debe añadirse la información solicitada con frecuencia por los ciudadanos y confirmada como procedente (art. 10.2). Todos ellos se centralizarán en un Portal de la Transparencia con el fin de facilitar el acceso de los ciudadanos a toda la información (art. 10).

El Consejo de Transparencia y Buen Gobierno desarrollará las actuaciones necesarias para conocer y resolver sobre la materia y lo hará de acuerdo con un procedimiento que debe definirse reglamentariamente. A falta de concreción al respecto, las actuaciones pueden iniciarse tanto de oficio como por reclamación de los ciudadanos, que no precisan acreditar condición específica alguna respecto de la información, en especial la de interesado, y que tampoco tienen que acreditar una previa reclamación ante la administración, sino simplemente dar cuenta de la ausencia de determinada información.

Como conclusión de esas actuaciones, el Consejo puede dictar resoluciones en las que se establezcan las medidas necesarias para el cese del incumplimiento y el inicio de las actuaciones disciplinarias que procedan. Parece que debe entenderse que las resoluciones del Consejo no operan de forma ejecutiva, pero pueden dar lugar a las medidas disciplinarias a las que la ley se remite ("tendrá la consideración de infracción grave a los efectos de aplicación a sus responsables del régimen disciplinario previsto en la correspondiente normativa reguladora"). No nos encontramos ante una posible aplicación del régimen sancionador en materia de transparencia, que no existe en la ley, sino del régimen general disciplinario o de la "correspondiente normativa reguladora". Esta expresión parece remitirse a la responsabilidad disciplinaria en materia de función pública. Se trata de un caso diferente al impulso de expedientes sancionadores previstos en el Título II de la ley, que se refiere a las obligaciones de buen gobierno que afectan a los altos cargos, diferentes de las propias en materia de transparencia. Además, los incumplimientos del criterio del órgano de control pueden dar lugar a un impulso del posible expediente sancionador; a lo sumo, a la emisión de un dictamen motivado, pero no a la incoación de un expediente propio del órgano de control, puesto que no se le atribuye competencia específica en este terreno.

A las funciones más propias en esta materia deben añadirse las que con carácter general se atribuyen al Consejo relacionadas con el control de la publicidad activa. El órgano, "para la consecución de sus objetivos", entre los que se cuenta el cumplimiento de las obligaciones de publicidad activa, puede "adoptar recomendaciones para el mejor cumplimiento" de esas obligaciones; asesorar en materia de publicidad activa; informar los proyectos normativos de carácter estatal que afecten a esta forma de publicidad; evaluar de forma general el grado de aplicación de la ley mediante la memoria anual que debe presentar ante las Cortes Generales; 
promover la elaboración de borradores de recomendaciones y de directrices y normas de desarrollo de buenas prácticas en materia de transparencia, acceso a la información pública y buen gobierno; y actividades de formación y sensibilización sobre publicidad activa.

Aunque en principio las funciones tratadas se atribuyen al Consejo como órgano colegiado, sin embargo la ley matiza que va a corresponder a su Presidente ejercer la función de "adoptar criterios de interpretación uniforme" de las obligaciones de publicidad activa y "velar por el cumplimiento de las obligaciones de publicidad contenidas en el Capítulo II del Título I de acuerdo con lo previsto en el art. 9 de esta Ley". Por tanto, las competencias más relevantes en este terreno se concentran en la presidencia.

\subsection{La resolución de los recursos contra las resoluciones de las solicitudes de acceso a la información pública}

Las posibles impugnaciones administrativas de lo resuelto en las solicitudes de acceso a la información pública se conocen por el Consejo de Transparencia y Buen Gobierno. Se habilita una reclamación específica ante él, con carácter potestativo y previo a su impugnación jurisdiccional. Se trata de un recurso administrativo que sustituye a los ordinarios previstos en la legislación de procedimiento administrativo. Efectivamente, el art. 107.2 de esta ley prevé la posibilidad de sustituir el recurso ordinario por otra forma de impugnación administrativa, incluida la conciliación, la mediación y el arbitraje "ante órganos colegidos o comisiones específicas no sometidas a instrucciones jerárquicas". La primera ventaja que se atribuye a esta alternativa es la desviación de la solución del recurso hacia una instancia diferente de la propia administración que dictó el acto impugnado, lo que aporta más posibilidades de revisión, o al menos de reexamen, lo que no es poca cosa si tenemos en cuenta el escaso grado de receptividad cuando se plantean recursos administrativos ordinarios. Además, el hecho de que el órgano que va a resolver sea creado ad hoc y reúna la condición de independiente (no sometido a instrucciones jerárquicas) hace que el grado de objetividad y aceptación del criterio aumente considerablemente, con lo que disminuye el nivel de posible litigiosidad.

Los requisitos previstos para este mecanismo sustitutivo son el establecimiento a través de norma con rango de ley, en este caso la LETAI; que lo específico de la materia lo justifique, lo que parece evidente en transparencia; $y$, como ya señalamos, que no se trate de órganos sometidos a instrucciones jerárquicas. Esta última condición remite necesariamente a un estatus de independencia en el funcionamiento de los órganos alternativos. Esta condición parece clara, por ejemplo, cuando la función se asigna a los defensores del pueblo. Por el contrario, algún sector ha puesto en cuestión que la necesaria independencia del órgano se dé en el caso del Consejo de Transparencia y Buen Gobierno adscrito al Ministerio de Hacienda y Administraciones Publicas. Por ejemplo, el XIII Informe sobre Derechos Humanos: Transparencia e Información Pública de la FIO señala que aunque debe actuar, tal y como establece la ley, con 
autonomía y plena independencia en el cumplimiento de sus fines, "no se trata de una independencia muy robustamente guarnecida por la norma. Su regulación legal se ha desarrollado por el Real Decreto 919/2014. El Consejo de Transparencia se compone de Comisión y Presidente. La Presidencia es propuesta por el Gobierno y aprobada por la mayoría absoluta del Congreso. La primera titular del cargo, nombrada en noviembre de 2014, poco antes desempeñó el cargo de Directora General de Modernización Administrativa. En España no hay una tradición de gran independencia de las autoridades independientes".

Otra importante objeción en ese mismo sentido se concreta en la concentración de una relevante competencia en la presidencia; como vimos, le corresponde, entre otras, la función de "conocer de las reclamaciones que se presenten en aplicación del art. 24 de esta Ley" (art. 38.2), precisamente la importante función que analizamos ${ }^{10}$.

Por lo que se refiere al procedimiento del recurso sustitutivo, debe interponerse en el plazo de un mes contado desde el día siguiente al de la notificación del acto impugnado o desde el día siguiente al efecto del silencio. Cuando la denegación del acceso se fundamente en la protección de derechos o intereses de terceros se otorgará audiencia previa a las personas que puedan ser afectadas para que aleguen lo que deseen. Finalmente, el plazo máximo para resolver y notificar la resolución será de tres meses, transcurrido el cual la reclamación se entenderá desestimada. Las resoluciones del Consejo de Transparencia y Buen Gobierno se publicarán, previa disociación de los datos de carácter personal que contuvieran, por medios electrónicos, una vez se hayan notificado a los interesados. Así se viene haciendo en la página web del Consejo (www.consejodetransparencia.es). Además, las resoluciones que se dicten deben comunicarse al Defensor del Pueblo ${ }^{11}$.

El recurso sustitutivo se descarta para los casos de instituciones constitucionales o autonómicas, respecto de cuyas resoluciones sólo cabrá la interposición de recurso contencioso-administrativo (art. 23.2).

\subsection{Funciones generales del consejo estatal}

Las "otras funciones" del Consejo que contiene el art. 38 LETAI son: "a) Adoptar recomendaciones para el mejor cumplimiento de las obligaciones contenidas en esta Ley. b) Asesorar en materia de transparencia, acceso a la información pública y buen gobierno. c) Informar preceptivamente los proyectos normativos de carácter estatal que desarrollen esta Ley o que estén relacionados con su objeto. d) Evaluar el grado de aplicación de esta Ley. Para ello, elaborará anualmente una memoria en la que se incluirá información sobre el cumplimiento de las obligaciones previstas y que será

\footnotetext{
${ }^{10}$ Esta disposición parece contradecir lo dispuesto anteriormente en el art. 24.6, aunque la mención general de éste parece referida más bien a la atribución genérica de la competencia al Consejo, resultando más específica la prevista a favor del Presidente que contiene el art. 38.2.

${ }^{11}$ El art. 24 LETAI señala: ... 2. La reclamación se interpondrá en el plazo de un mes a contar desde el día siguiente al de la notificación del acto impugnado o desde el día siguiente a aquel en que se produzcan los efectos del silencio administrativo.
} 
presentada ante las Cortes Generales. e) Promover la elaboración de borradores de recomendaciones y de directrices y normas de desarrollo de buenas prácticas en materia de transparencia, acceso a la información pública y buen gobierno. f) Promover actividades de formación y sensibilización para un mejor conocimiento de las materias reguladas por esta Ley. g) Colaborar, en las materias que le son propias, con órganos de naturaleza análoga. h) Aquellas otras que le sean atribuidas por norma de rango legal o reglamentario".

En este mismo artículo se contienen las específicas funciones del Presidente del Consejo: "a) Adoptar criterios de interpretación uniforme de las obligaciones contenidas en esta Ley. b) Velar por el cumplimiento de las obligaciones de publicidad contenidas en el Capítulo II del Título I de acuerdo con lo previsto en el artículo 9 de esta ley. c) Conocer de las reclamaciones que se presenten en aplicación del artículo 24 de esta Ley. d) Responder las consultas que, con carácter facultativo, le planteen los órganos encargados de tramitar y resolver las solicitudes de acceso a la información. e) Instar el inicio del procedimiento sancionador previsto en el Título II de esta ley. El órgano competente deberá motivar, en su caso, su decisión de no incoar el procedimiento. f) Aprobar el anteproyecto de presupuesto. g) Aquellas otras que le sean atribuidas por norma de rango legal o reglamentario".

\subsection{Funciones en el ámbito sancionador}

Como ya señalamos, la LETAI no contiene un aparato sancionador propio en materia de transparencia y acceso a la información pública; en cambio, el Título II, relativo al buen gobierno, sí cuenta con un amplio régimen sancionador (arts. 27-32 LETAI). Lo primero se suple en parte por medio de la remisión a las posibles actuaciones disciplinarias "que procedan", especialmente en caso de incumplimiento reiterado de las obligaciones de publicidad activa, que "tendrá la consideración de infracción grave". Como vimos, no nos encontramos ante un régimen sancionador en materia de transparencia, sino ante la remisión al régimen general disciplinario de la "correspondiente normativa reguladora", esto es, la responsabilidad disciplinaria en materia de función pública. Las posibilidades del órgano de control ante los incumplimientos pueden dar lugar al impulso de una sanción o a la emisión de un dictamen motivado, pero no a la incoación de uno propio.

El régimen sancionador por remisión genérica a la "correspondiente normativa" se limita a los casos de publicidad activa; en las solicitudes de información no se prevé amparo de carácter sancionador ante posibles incumplimientos. Sin embargo, consideramos que nada impide que las mismas circunstancias que motivan un impulso sancionador para incumplimientos en las obligaciones de publicidad activa den lugar a ese mismo impulso ante incumplimientos en materia de acceso a la información pública, por ejemplo por incumplimiento de las resoluciones a los recursos sustitutivos.

El amplio régimen sancionador del Título II de la LETAI en principio no afecta a lo relativo a las obligaciones de transparencia, aunque es 
evidente la interconexión entre ambas materias en lo que se refiere a sus principios y obligaciones de los altos cargos.

\section{EL VALEDOR DO POBO COMO COMISIONADO DE LA TRANSPARENCIA Y PROTAGONISTA DE LA COMISIÓN DE TRANSPARENCIA}

Ya vimos que la LETAI prevé que las comunidades autónomas puedan crear un órgano de control propio o atribuir esa función al Consejo estatal de forma convencional y mediante el pago que se acuerde. Sin embargo, ese posible órgano propio parece referido sólo a las funciones de resolución de los recursos sustitutivos. Con ello surge la duda de si la intención de la ley era que las comunidades autónomas no pudieran ejercer funciones propias generales, salvo las del recursos sustitutivo, algo que se descartó de inmediato por resultar contrario al principio de autonomía y a la auto-organización de las comunidades autónomas; o, con mayor sentido, si en ausencia de órgano propio autonómico para el control general podría actuar el del Estado, lo que también debe descartarse.

Las leyes autonómicas conformaron diferentes sistemas de reclamación; en unos casos firmaron el convenio con el Consejo, como vimos; en otros atribuyeron la función general de control y la específica relativa a los recursos sustitutivos a órganos ad hoc; y en otros recurrieron a instituciones autonómicas ya existentes, como los defensores autonómicos, con un claro propósito de ahorro presupuestario ${ }^{12}$.

Un papel de relevancia atribuido a la figura del defensor del pueblo autonómico se da en el caso del Procurador del Común, el defensor del pueblo de Castilla y León. La Ley 3/2015, de 4 de marzo, de Transparencia y Participación Ciudadana de Castilla y León, crea el Comisionado y la Comisión de Transparencia autonómicos y designa al Procurador como Comisionado, con la finalidad de "velar por el cumplimiento de las obligaciones de publicidad activa y salvaguardar el ejercicio del derecho de acceso a la información pública" (art. 11.2), mientras que la Comisión se integrará con el propio comisionado -su titular-, que la presidirá, el adjunto, y el secretario, con voz y voto, que será designado por el procurador entre las personas al servicio de la institución (art. 12). El Comisionado, que se identifica con la institución del Procurador del Común, tiene atribuidas las funciones generales de control, mientras que la Comisión conoce las reclamaciones de carácter potestativo y sustitutivas de los recursos ordinarios en materia de acceso a la información pública y previas a su impugnación en vía contenciosoadministrativa (art. 8).

Este fue el modelo seguido en gran parte por el proyecto de ley gallega, aunque la versión finalmente aprobada incluyó importantes novedades. La LGT atribuye al Valedor do Pobo la condición de Comisionado da Transparencia, con funciones similares a las de Castilla y León (art. 32),

\footnotetext{
${ }^{12}$ El plan estratégico del Consejo estatal expone de forma pormenorizada las diferentes
} opciones de cada C.A. (www.consejodetransparencia.es). 
esto es, referidas al control general en materia de transparencia. Crea también la Comisión da Transparencia para conocer de los recursos sustitutivos contra las resoluciones de las solicitudes de acceso a la información (art. 33). En esta Comisión se integran dos de los miembros del Valedor, su titular, que la preside, y el adjunto, como vicepresidente, y cuatro vocales de diferente origen (un representante de la Comisión Interdepartamental de Información y Evaluación de la Xunta de Galicia; otro del Consello Consultivo de Galicia; otro del Consello de Contas; y otro de la Federación Galega de Municipios e Provincias).

Como vemos, el modelo castellano-leonés es coincidente con el gallego en lo que se refiere a la atribución de la competencia general de control a la institución del Valedor do Pobo; pero difieren en cuanto al tratamiento de los recursos sustitutivos, puesto que la Comisión castellano-leonesa está integrada únicamente por miembros del Procurador del Común, mientras que la Comisión gallega la integran miembros del Valedor do Pobo, su titular y el adjunto, pero también cuatro de otra procedencia.

El modelo gallego se diferencia en mayor medida del estatal, puesto que éste articula una fórmula colegiada para el control general de la transparencia, mientras que en Galicia ese control corresponde en exclusiva a una institución característicamente unipersonal como el Valedor do Pobo; y también se aleja del modelo estatal en cuanto a la atribución de la competencia para resolver los recursos sustitutivos, puesto que en el Estado esa función corresponde a la presidencia, y en cambio en Galicia se atribuye al órgano colegiado.

Así, la LGT incorpora como funciones propias del Valedor do Pobo, como Comisionado da Transparencia, las siguientes (art. 32):

- Responder a las consultas que se planteen en relación con la aplicación de la ley.

- Adoptar recomendaciones para mejor cumplimiento de los deberes legales derivados de la ley en materia de transparencia y buen gobierno, oída la comisión.

- Asesorar en materia de transparencia, acceso a la información y buen gobierno.

- Emitir informes previos sobre proyectos de ley o de reglamentos en materia de transparencia y buen gobierno, oída la Comisión.

- Efectuar, por iniciativa propia o a causa de denuncia, requerimientos para la enmienda de los incumplimientos de los deberes en materia de publicidad activa.

- Aquellas otras funciones que le sean atribuidas por norma legal.

Por otra parte, en razón de su función de dirección y organización de la labor propia de la Comisión da Transparencia realizará el desarrollo burocrático de la misma -recepción, notificaciones, publicidad...-, en especial, las propuestas de resolución.

Los miembros de la Comisión da Transparencia fueron nombrados por resolución de la valedora do pobo de 15 de abril de 2016 (DOG n 78, de 25 de abril de 2016), y empezó a funcionar con su reunión constitutiva de 10 de mayo de ese mismo año. 
Finalmente, como función añadida última, el art. 36 de la LGT señala que el Valedor do Pobo incluirá en su informe presentado anualmente ante el Parlamento de Galicia, previsto en la ley reguladora de la institución, un epígrafe relativo al grado de aplicación y cumplimiento de la ley de transparencia, en la cual recogerá, en todo caso: los criterios interpretativos y recomendaciones; la relación de reclamaciones; la actividad de asesoramiento; los requerimientos efectuados; y la evaluación del grado de cumplimiento de los deberes de publicidad activa por parte de los sujetos afectados.

En definitiva, la ley gallega asigna nuevas funciones al Valedor do Pobo; como Comisionado da Transparencia desarrolla una intervención general para el control y la garantía de la transparencia, en particular para la efectividad de sus principios y sus normas, el control de la publicidad activa y la persecución de sus incumplimientos; y como institución en la que se incardina la Comisión da Transparencia le corresponde la dirección y la aportación de la infraestructura de trabajo común para la resolución de las reclamaciones en materia de acceso a la información pública.

Al hilo de estas nuevas funciones debemos resaltar dos importantes aspectos. En primer término, que a la labor de control ordinario propia del Valedor do Pobo se superpone la de garantía, al menos en algunos concretos ámbitos, sobre todo en relación con los recursos sustitutivos. De acuerdo con su genuina naturaleza, los defensores del pueblo, entre los que se cuenta el Valedor do Pobo, realizan una función de control, no de garantía plena o "aseguramiento"13; por el contrario, las funciones en materia de transparencia se caracterizan por ir más allá del control asociado al ejercicio de la auctoritas de los defensores para entrar en el terreno de la garantía. El otro aspecto destacable es que el desarrollo de la labor del Valedor do Pobo en materia de transparencia no se rige por los principios comunes a su actuación ordinaria, fundamentalmente la aformalidad -o no sujeción a las leyes administrativas de procedimiento-, el carácter sumario de sus actuaciones, el principio pro-ciudadano, y la capacidad de resolver con base en criterios amplios, no sólo de legalidad, sino también de equidad, justicia y otros. Por el contrario, el ejercicio de las nuevas funciones se encuentra sometido de forma estricta al principio de legalidad y debe encauzarse a través de las leyes de procedimiento que rigen en el ámbito administrativo.

\footnotetext{
${ }^{13}$ Esa es la posición, por ejemplo, de García Morillo, que señala que "la garantía es el mecanismo jurídico que se utiliza para asegurar la adecuación de los comportamientos a las normas que deben regirlos". Este autor divide la garantía en dos fases de actuación. La primera tiene por objeto "la comprobación de la adecuación del comportamiento que es objeto de la garantía a las normas o principios que debieran regir dicho comportamiento", lo que identifica como el "control". Por su parte, la segunda fase de la estructura de la garantía vendría dada por las medidas que se prevén para casos de comportamientos inadecuados, para su corrección, un segundo elemento que llama "sancionador". Uno y otro elemento, control y sanción, conforman la garantía. Vid. J. GARCÍA MORILLO, El control parlamentario del Gobierno en el ordenamiento español, Congreso de los Diputados, Madrid, 1985, págs. 43-44, citado por P. CARBALLO ARMAS, op. cit., p. 152.
} 
Para el correcto desarrollo de las funciones que la ley gallega atribuye al Valedor su disposición adicional sexta prevé la necesidad de reordenar y reasignar los medios personales con los que cuenta la institución. Además, a través de su Disposición final tercera modifica el art. 10.2 de la Ley 6/1984, de 5 de junio, del Valedor do Pobo, y faculta al valedor para designar hasta a cinco asesores -denominación original de los técnicos en las diferentes instituciones de este tipo-, uno más que los que establecía ese mismo artículo con anterioridad.

\section{NUEVAS Y VIEJAS FUNCIONES DEL VALEDOR DO POBO EN MATERIA DE TRANSPARENCIA}

La caracterización de los sistemas de garantía mediante instancias independientes, al menos cuando resuelven los recursos sustitutivos, ha propiciado que muchas regulaciones hayan recurrido a los defensores del pueblo como instituciones adecuadas. Se trata instituciones caracterizadas de forma muy marcada por su independencia de origen y por el desarrollo autónomo de sus funciones, sobre todo la defensa de los derechos fundamentales y la supervisión de los poderes públicos.

De esta forma, a su papel ordinario la ley estatal y algunas leyes autonómicas añaden ciertos cometidos específicos, con diferencias según los casos. Así, la ley estatal prevé que uno de los miembros del Consejo estatal sea representante del Defensor del Pueblo, que además, como institución, debe recibir comunicación de todas sus resoluciones (arts. 10, 24 y 33), con la clara intención de conocer la doctrina general que se vaya creando y para posibilitar o dar pie a posibles actuaciones por parte del Defensor.

Parece claro que no existen posibles objeciones legales o de carácter institucional para la designación de los defensores como órganos encargados del control de la transparencia. Estas instituciones reúnen la condición inexcusable de ser órganos independientes (disposición adicional cuarta LETAI), y su actividad se percibe también como independiente por parte de los ciudadanos, conscientes de que su funcionamiento autónomo se encuentra salvaguardado por los presupuestos constitucionales, estatutarios y legales propios de los ombudsman. Cuentan, además, con amplia experiencia en el tratamiento de reclamaciones referidas a la aplicación del principio de transparencia. Y no es desdeñable el ahorro presupuestario que supone evitar crear un órgano nuevo.

Estas nuevas funciones se desempeñan por el Valedor como añadidas a las genuinas y principales; sin embargo, no son las únicas que desarrolla en el ámbito de la transparencia. Junto a las nuevas funciones, sigue desarrollando de forma principal su labor de control mediante quejas ciudadanas o de oficio y por medio de la publicidad de su actuación ante el Parlamento de Galicia; y muchas de las quejas y contenidos de los informes se refieren a la transparencia sin coincidir con las nuevas funciones, sino formando parte del trabajo más propio de los defensores. Desde su creación éstos han desarrollado una amplia labor en materia de transparencia, sobre todo en aspectos sectoriales de gran relevancia; han resultado numerosas y relevantes sus intervenciones en favor de la 
transparencia en la administración local (derecho de información de los grupos municipales de oposición), en materia ambiental (con el fin de facilitar la participación pública en decisiones ambientales y para el acceso sin restricciones a la justicia), o en materias estrictamente administrativas (interpretación adecuada del derecho general de acceso a los archivos y registros públicos).

Además, ambas funciones, la tradicional y la más reciente, están entrelazadas; la transparencia es un presupuesto para el correcto desempeño de la labor de control de los defensores. Los ciudadanos precisan conocer de lo público con carácter previo a las iniciativas de fondo que pretenden promover. Es determinante la facilidad y el nivel de acceso a los asuntos públicos en sentido amplio, ya sean asuntos de carácter general (planificaciones, proyectos...) o de interés particular (acceso a expedientes, motivación de los asuntos, respuesta a las solicitudes...). Por ello, en esta materia el papel del Valedor es doble; actúa con el fin de que el ciudadano esté suficientemente informado de los asuntos públicos $y$, al mismo tiempo, esa previa garantía de información permite al ciudadano plantearle reclamaciones derivadas de la información preliminar ${ }^{14}$. Así, el principio de transparencia tiene una especial relevancia en el desarrollo institucional de todos los defensores; por una parte, como elemento típico de su labor ordinaria de control de las administraciones, y por otra, como elemento central facilitador del papel de la ciudadanía a la hora de promover reclamaciones derivadas de la garantía previa de su derecho a conocer.

Otra función del Valedor, esta ya derivada de las nuevas leyes, será el cumplimiento de sus obligaciones en materia de publicidad activa y la resolución de las solicitudes de información pública que se le dirijan, puesto que se cuenta entre las instituciones sujetas a las exigencias de las leyes de transparencia ${ }^{15}$. Lo hará no como Comisionado da Transparencia o cabeza de la Comisión, sino como Valedor do Pobo.

Diferentes serás las funciones como Comisionado, que afectan a la práctica totalidad de la labor de control (y en algún caso de garantía) en materia de transparencia. En este caso se trata de una función también propia, esto es, del Valedor do Pobo como tal, pero en su condición de Comisionado da Transparencia.

Más alejadas de este perfil se encuentran las funciones que desarrolla en el seno de la Comisión da Transparencia, que ya no son, como las

\footnotetext{
${ }^{14}$ Se señala al respecto que "las defensorías españolas siempre tendrán que estar presentes en el tema, como garantes institucionales del derecho de acceso a la información y como entes que pueden efectuar campañas de divulgación de la transparencia y de colaboración en este sentido", J. J. FERNÁNDEZ RODRÍGUEZ, op. cit., p. 76.

${ }^{15}$ Los defensores se encuentran entre las instituciones que se someten a las exigencias de la LETAI, junto con la Casa de SM El Rey, el Congreso de los Diputados, el Senado, el Banco de España, el Tribunal Constitucional, el Consejo General del Poder Judicial, el Consejo de Estado, el Tribunal de Cuentas o el Consejo Económico y Social, en relación a sus actividades sujetas al Derecho administrativo (art. 23), a las que se unen las instituciones análogas de las comunidades autónomas.
} 
anteriores, propias del Valedor, sino de la entidad creada ad hoc para la resolución de los recursos sustitutivos, en la que el Valedor como tal sólo participa aportando dos de sus miembros -un tercio del total- y como institución de apoyo burocrático. Es conveniente resaltar que la actuación de la Comisión no es la actuación del Valedor do Pobo.

Podemos resumir todas las posibles formas de actuar del Valedor en este terreno de la siguiente forma: $1^{a}$, actuación genuina; $2^{a}$, actuación para cumplir las obligaciones propias de publicidad activa y respuesta a las solicitudes de información pública; $3^{a}$, actuaciones como Comisionado da Transparencia (consultas, recomendaciones, asesoramiento, informes sobre proyectos de ley o reglamentos, requerimientos de enmienda de incumplimientos); 4a, actuaciones en el seno de la Comisión da Transparencia (resoluciones de los recursos sustitutivos).

La diferente naturaleza de todas ellas es determinante para establecer el régimen jurídico y los recursos aplicables en cada caso. En el caso de la actuación genuina del Valedor $\left(1^{a}\right)$, no se encuentra sometida al procedimiento administrativo (actuación aformal), sus valoraciones son criterios de autoridad no vinculantes, y sus decisiones no son recurribles, ni ante el propio Valedor ni ante los tribunales. La actuación para cumplir sus obligaciones en materia de transparencia ( $\left.2^{a}\right)$ se plasma en resoluciones formales que deben respetar las normas de procedimiento y son recurribles en vía judicial (ante el Tribunal Superior de Justicia de Galicia). No será posible promover denuncias o interponer recursos administrativos contra ellas, puesto que en ambos casos la competencia para conocerlos coincidiría (en todo o en parte) en el mismo órgano revisor ${ }^{16}$. Sí cabe, como en el caso de las quejas, una petición informal de revisión. Las actuaciones como Comisionado da Transparencia (3a) también son actuaciones propias, pero por tratarse de actos con carácter meramente indicativo (recomendaciones, asesoramiento...) se asimilan a las actuaciones genuinas, por lo que no tienen fuerza vinculante y no pueden ser recurridas. Finalmente, las actuaciones de la Comisión da Transparencia $\left(4^{\mathrm{a}}\right)$ no son propias del Valedor, sino de la Comisión, que es un órgano colegiado regido por las normas de este tipo de órganos y por la autorregulación de que se dote. Sus actos deben desarrollarse con arreglo a las normas del Derecho Administrativo, y sus resoluciones son recurribles en vía contencioso-administrativa, pero en este caso el fuero será el ordinario, no el atribuido de forma específica al Valedor.

A la vista de la anterior división se aprecia un terreno en que la diferencia entre las funciones genuinas y las nuevas no aparece clara; se trata de las funciones como Comisionado, en especial en lo que se refiere a la labor de asesorar, responder a consultas o formular recomendaciones. Observamos que son coincidentes con las desarrolladas de forma habitual por el

\footnotetext{
${ }^{16}$ La ley estatal establece que no existirá reclamación sustitutiva, por lo que la única posibilidad de impugnación se concreta en la vía judicial. Esto evita tener que aclarar qué sucede cuando se plantea una reclamación contra el defensor y este reúne también la condición de órgano de control administrativo de la transparencia. También descarta que otros órganos distintos de los jurisdiccionales puedan pronunciarse en contra de lo resuelto por los defensores.
} 
Valedor en el desarrollo de su función ordinaria, generalmente relacionada con las quejas, que en ocasiones se plantean como consultas o peticiones de asesoramiento sobre problemas. La única forma de discernir entre el ejercicio de una u otra función será la pura casuística; la labor ordinaria del Valedor sigue siendo la genuinamente atribuida por su ley y por tanto la mayor parte de las iniciativas ciudadanas seguirán siendo quejas y deben tramitarse como tales. Sólo deben considerarse iniciativas para que actúe como Comisionado las que específicamente reclamen asesoramiento - las consultas sobre transparencia, y las recomendaciones que deriven del tratamiento de su función general como Comisionado o como miembro de la Comisión, pero no las recomendaciones derivadas de sus habituales procedimientos de queja, que por ello no tienen que ser previamente conocidas por la Comisión. Las otras funciones como Comisionado, los informes sobre proyectos normativos o los requerimientos de enmienda, no plantean dudas, puesto que son claramente diferentes de las funciones ordinarias.

Aún existe otro posible campo de actuación a añadir a los anteriores. La actuación de los consejos de control de la transparencia es puramente administrativa y por ello puede ser supervisada por los defensores en el ejercicio de su función ordinaria. No se prevén excepciones subjetivas que permitan obviar la labor del defensor o espacios objetivos que se consideren exentos ${ }^{17}$, salvo previsión de la propia ley. Esta excepción legal se dará con una lógica indudable cuando las funciones de los consejos o comisiones se atribuya a los defensores, como vimos que sucede en Castilla y León, donde la Comisión está formada por tres miembros y todos ellos forman parte del Procurador del Común. La duda puede surgir en casos como el gallego; la Comisión da Transparencia está formada no sólo por miembros del Valedor, sino por otros representantes institucionales, por lo que no es descartable el ejercicio de supervisión ordinaria que mencionamos. Esa posibilidad debe valorarse de manera muy restrictiva, puesto que se trataría de quejas contra la actuación de una Comisión presidida por el valedor y cuyo vicepresidente es su adjunto. Esto nos lleva a pensar que en muy escasas ocasiones se podrían admitir a trámite este tipo de quejas.

El papel de los defensores -y por tanto también del Valedor- no se agota en lo expuesto; a la vertiente externa o ad extra que acabamos de tratar se une un elemento que podemos denominar ejemplarizante, de vital importancia en instituciones de auctoritas, que deben ser especialmente rigurosas a la hora de establecer sus propios umbrales de transparencia ${ }^{18}$.

\footnotetext{
${ }^{17}$ Así lo señala J. J.FERNÁNDEZ RODRÍGUEZ, op. cit., p. 76.

${ }^{18}$ La vertiente interna de la transparencia, tal y como la denomina Fernández Rodríguez, "alude a que este tipo de órganos deben ser especialmente escrupulosos en el cumplimiento de las exigencias de la transparencia". J. J. FERNÁNDEZ RODRÍGUEZ, op. cit., p. 75.
} 


\section{BIBLIOGRAFÍA}

FERNÁNDEZ RODRÍGUEZ, J. J., Defensorías del Pueblo en España: una visión prospectiva, Universidad de Alcalá de Henares, 2014.

GARCÍA MORILLO, J., El control parlamentario del Gobierno en el ordenamiento español, Congreso de los Diputados, Madrid, 1985.

ORDÓÑEZ SOLÍS, D., "El derecho de información del ciudadano, la protección de datos personales y la transparencia de la Administración", en Revista del Poder Judicial, núm. 73, 2004.

SENDÍN GARCÍA, M. A., "Transparencia y acceso a la información pública", en J. Rodríguez Arana y M. A. Sendín García, Transparencia, acceso a la información y buen gobierno, Comares, Granada, 2014.

VV.AA., Transparencia e información pública, XIII Informe sobre derechos humanos, Federación Iberoamericana del Ombudsman, Trama Editorial, Madrid, 2015. 